\title{
HOME IS THE NEW GYM: EXERGAME AS A POTENTIAL TOOL TO MAINTAIN ADEQUATE FITNESS LEVELS ALSO DURING QUARANTINE
}

original paper

( ) University School of Physical Education in Wroclaw

DOI: https://doi.org/10.5114/hm.2020.94826

\section{CRISTINA CORTIS ${ }^{1}$, GIUSEPPE FRANCESCO GIANCOTTI ${ }^{1}$, ANGELO RODIO ${ }^{1}$, ANTONINO BIANCO ${ }^{2}$, ANDREA FUSCO ${ }^{1}$}

${ }^{1}$ Department of Human Sciences, Society and Health, University of Cassino and Lazio Meridionale, Cassino, Italy

${ }^{2}$ Department of Psychology, Educational Science and Human Movement, University of Palermo, Palermo, Italy

\begin{abstract}
Purpose. With the coronavirus outbreak, the preventive measures include staying at home and isolation, increasing sedentary behaviours and risk for worsening of chronic diseases. To explore alternative forms of home-based physical activity, the study aim was to evaluate physiological (heart rate [HR], respiratory exchange ratio [RER], oxygen consumption [نं $\left.{ }_{2}\right]$, energy expenditure [EE], metabolic equivalent task [MET]) and psychological (session rating of perceived exertion [sRPE], enjoyment) parameters of real (Zumba ${ }^{\circledR}$ class [ZC]) and exergame (Zumba ${ }^{\circledR}$ Fitness Rush [ZFR]) activities in relation to sex.

Methods. Overall, 12 female (age: $24.7 \pm 0.9$ years) and 8 male (age: $25.3 \pm 2.1$ years) college students randomly performed 2 experimental 60-min sessions, ZC and ZFR, during which HR (expressed as percentage of individual maximal HR [\%HRmax]), $\dot{\mathrm{V}} \mathrm{O}_{2}$, RER, MET and EE were measured. After each session, sRPE and Physical Activity Enjoyment Scale (PACES) were used to monitor exercise intensity and enjoyment, respectively.

Results. Main effects for sex $(p=0.02)$ and modality $(p<0.0001)$ emerged for $\%$ HRmax, with women showing higher values than men and ZC showing higher values than ZFR. EE presented main effects for sex $(p<0.0001)$ and modality $(p=0.0002)$, with higher values in men and in ZC. Main effect $(p=0.0001)$ for modality emerged also for $\dot{\mathrm{VO}}_{2}$ and MET, with higher values in ZC regardless of sex. No significant differences were observed for RER, sRPE, or PACES.

Conclusions. Although ZC elicited higher cardiovascular and metabolic responses, ZFR, classified as a moderate-to-vigorous activity, could be used to maintain regular physical activity in a safe home environment during the coronavirus crisis.
\end{abstract}

Key words: COVID-19, home training, energy expenditure, heart rate, oxygen consumption, Zumba

\section{Introduction}

Although regular levels of physical activity (PA) have significant health benefits and contribute to preventing non-communicable diseases, 1 in 4 adults and more than $80 \%$ of the adolescent population in the world are not active enough [1]. Insufficient PA is one of the leading risk factors for death worldwide and according to the World Health Organization (WHO), policies to address insufficient PA are operational in 56\% of WHO member states with the aim to reduce insufficient PA by $10 \%$ by 2025 [1]. To increase the amount of PA in the general population, guidelines and recommendations are available [2, 3]; to achieve and maintain good health, adults should include moderate-intensity (met- abolic equivalent task [MET] values ranging from 4.8 to 7.1) activity for 150-300 minutes per week or vigorous-intensity (MET values ranging from 7.2 to 10.1) activity for 75-150 minutes per week, or an equivalent combination, on 2 or more days per week [2, 3].

With the on-going coronavirus outbreak $[4,5]$, directives against participating in several activities, including sport, exercise, and PA, have been put in place by the health authorities [6], thus increasing sedentary behaviours, reducing regular PA, and leading to an increased risk for and potential worsening of chronic health conditions [7]. In this context, to encourage PA, not only exercise, but also other forms of home-based activities are recommended as effective measures to stay healthy and maintain the immune system func-

Correspondence address: Cristina Cortis, Department of Human Sciences, Society and Health, University of Cassino and Lazio Meridionale, Via S. Angelo - Località Folcara, 03043 Cassino (FR), Italy, e-mail: c.cortis@unicas.it

Received: March 19, 2020

Accepted for publication: April 23, 2020

Citation: Cortis C, Giancotti GF, Rodio A, Bianco A, Fusco A. Home is the new gym: exergame as a potential tool to maintain adequate fitness levels also during quarantine. Hum Mov. 2020;21(4):79-87; doi: https://doi.org/10.5114/hm.2020.94826. 
tion in the current precarious environment [7]. While the usage of media such as video games has traditionally been associated with sedentary lifestyles and inactivity [8], the combination of video games and gross motor activity (active video games [AVGs] or exergaming) could contribute to meeting PA recommendations $[9,10]$, especially when exercise at home is the only option to avoid the airborne coronavirus while maintaining adequate fitness levels [7].

AVGs have been reported to improve mood and enjoyment compared with conventional forms of exercise $[11,12]$, providing encouragement to exercise, particularly for those who may be reluctant to engage in more traditional forms of PA [13]. As psychological factors such as fun and enjoyment are direct determinants of engagement in PA [14], AVGs seem to be a potential strategy to be used in reducing physical inactivity time, increasing adherence to exercise programs, and promoting the enjoyment of PA $[15,16]$, even in the current situation, when coping stress and anxiety is of particular concern [6].

Measurements of PA intensity, rating of perceived exertion (RPE), session RPE (sRPE), and energy expenditure (EE) have shown that AVGs elicit physiological intensity levels equal to those of moderate and/or vigorous PA in healthy adults [12, 17]. In particular, MET values ranging from 2.8 to 3.8 , RPE (on a 6-20 scale) ranging from 9.6 to 11.4 , and EE ranging from 24.6 to $32.2 \mathrm{kcal}$ have been reported in adventure and dance games [12], while MET values ranging from 5.7 to 6.4, RPE (on a category-ratio 10 scale) ranging from 4.2 to 4.7 , and EE ranging from 5.3 to $8.3 \mathrm{kcal} \cdot \mathrm{min}^{-1}$ have been observed in single- and multi-player dancing games [17]. When compared with traditional exercise such as treadmill walking [18], whole-body AVGs of same duration (i.e., 10 minutes) have been reported to contribute to higher peak heart rate (HR) $(115 \pm 18$ vs. $138 \pm 23$ beats $\left.\cdot \min ^{-1}\right)$, MET $(7 \pm 2$ vs. $11 \pm 4)$, and oxygen consumption $\left(\dot{\mathrm{VO}}_{2}\right)\left(25 \pm 5\right.$ vs. $\left.40 \pm 13 \mathrm{ml} \cdot \mathrm{kg}^{-1} \cdot \mathrm{min}^{-1}\right)$.

As opposed to the motion sensors characterizing several AVGs (i.e., gyroscopes, accelerometers, pressuresensitive tables and mats, modified ergometers, and laser beams), the Xbox 360 associated with Kinect (Microsoft, Redmond, USA) uses a camera combined with an infrared-based 3D depth sensor for full-body 3D motion capturing and joint tracking. Without the need to attach markers on the body, Kinect gives the tremendous opportunity to replicate real movements without interferences, capturing players' actual movement and giving instant feedback, especially during dance-based fitness activities. Aiming to provide a total body interactive workout while dancing naturally hands-free, Xbox Kinect 360 has released different
AVGs focusing on Zumba ${ }^{\circledR}$, a fitness dance that combines Latin rhythms and aerobics and incorporates elements of strength, balance, and endurance training. Therefore, Zumba ${ }^{\circledR}$ Fitness, Zumba ${ }^{\circledR}$ Fitness Rush (ZFR), and Zumba ${ }^{\circledR}$ Fitness Core AVGs have been developed, enabling single- and double-player modality $[17,19]$. Evaluating short-term effects of virtual Zumba ${ }^{\circledR}$ (22-min session), Da Silva Neves et al. [20] reported a significant increase in diastolic and systolic blood pressure and $H R$ values, supporting the feasibility of AVG use in PA programs, although no information related to energy cost was provided. Investigating EE and intensity of different forms of AVGs, Howe et al. [21] showed in Zumba ${ }^{\circledR}$ Fitness AVG an average exercise HR of 139 beats $\cdot \mathrm{min}^{-1}$, $\dot{\mathrm{V}} \mathrm{O}_{2}$ above resting of $19.6 \mathrm{ml} \cdot \mathrm{kg}^{-1} \cdot \mathrm{min}^{-1}, 7.4 \mathrm{MET}$, and $\mathrm{EE}$ of $6.8 \mathrm{kcal} \cdot \mathrm{min}^{-1}$, suggesting that AVGs qualified as moderate-to-vigorous PA and could contribute to the recommended dose of PA for weight management in young adults. However, these researches included only short bouts of exercise performed with AVGs (7-22 minutes), thus not reflecting the typical duration of a PA session, namely 45-60 minutes, or the real use of AVGs. Only recently, Schneekloth and Brown [19] observed no differences in maximal HR, minutes of light and moderate PA, or number of steps taken in a small sample (i.e., 8 adult women) engaging in ca. 60 minutes of a real and AVG Zumba ${ }^{\circledast}$ class. However, PA intensity was only estimated by means of HR and accelerometer data, and no EE data were reported.

When prolonged home stay is necessary, such as during the current coronavirus outbreak, the development of AVG and technological solutions could play a crucial role in exercise [7, 22, 23]. Therefore, aiming to provide an alternative, feasible, and engaging form of PA, able to give an efficient stimulus to improve the individuals' fitness levels, the purpose of this study was to evaluate sex-related physiological (i.e., $\mathrm{HR}, \mathrm{VO}_{2}$, respiratory exchange ratio [RER], and EE) and psychological (i.e., sRPE and enjoyment) parameters of $\mathrm{Zumba}^{\circledR}$ class (ZC) and ZFR.

\section{Material and methods}

\section{Experimental approach to the problem}

To evaluate the sex-related physiological and psychological parameters of ZC and ZFR, the study was performed over an 11-day period, during which familiarization, preliminary assessments, and experimental sessions were organized, as shown in Figure 1.

Familiarization sessions were held to ensure adequate training with ZC and ZFR choreography in order 


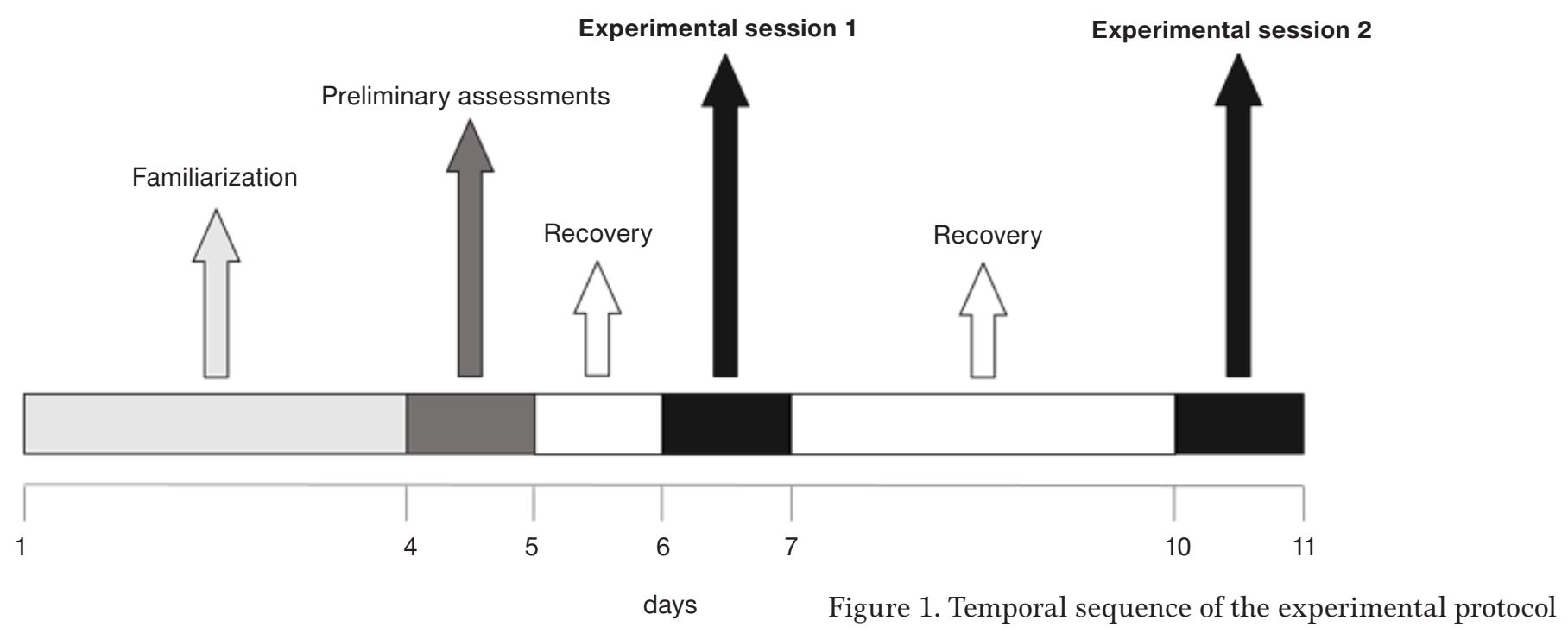

to avoid any potential learning effect on the results, and to familiarize subjects with the entire experimental protocol and procedures.

During the preliminary assessments session, data regarding anthropometric characteristics, aerobic capacity $\left(\dot{\mathrm{V}}_{2} \max \right)$, and PA level were recorded. To avoid any inter-observer variability, a single experienced researcher (G.F.G.) carried out all data collection, performed in the afternoon in the Sport and Exercise Physiology Laboratory (temperature: $27.1 \pm 1.6^{\circ} \mathrm{C}$, humidity: $43.8 \pm 10.3 \%$ ). Body weight and height were measured by using scales with integrated stadiometer with a precision of $0.1 \mathrm{~kg}$ and $0.1 \mathrm{~cm}$ (Seca, model 709, Vogel \& Halke, Hamburg, Germany), while Queens College Step Test (QCST) was administered to estimate $\dot{\mathrm{V}}_{2} \max$. The test required stepping up and down a 41.3 -cm step at the frequency of 22 steps $\cdot \mathrm{min}^{-1}$ $\left(88\right.$ beats $\left.\cdot \mathrm{min}^{-1}\right)$ for women and 24 steps $\cdot \mathrm{min}^{-1}$ $\left(96\right.$ beats $\cdot \mathrm{min}^{-1}$ ) for men, for a total of 3 minutes (metronome was used to monitor the stepping cadence) [24]. After completion of the exercise, the carotid pulse rate was measured for 15 seconds, from the $5^{\text {th }}$ to the $20^{\text {th }}$ second $\left(\mathrm{HR}_{\mathrm{QCST}}\right)$ of the recovery period. The following equations were used for the estimation of $\mathrm{VO}_{2} \max$ $\left(\mathrm{ml} \cdot \mathrm{kg}^{-1} \cdot \mathrm{min}^{-1}\right)$ [24]:

$$
\begin{gathered}
\text { Women: } \dot{\mathrm{VO}}_{2} \max =65.81-\left[0.1847 \cdot\left(\mathrm{HR}_{\mathrm{QCST}} \cdot 4\right)\right] \\
\text { Men: } \dot{\mathrm{VO}}_{2} \max =111.33-\left[0.42 \cdot\left(\mathrm{HR}_{\mathrm{QCST}} \cdot 4\right)\right]
\end{gathered}
$$

The results showed estimated $\mathrm{V}_{2}$ max values of $39.5 \pm 4.1 \mathrm{ml} \cdot \mathrm{kg}^{-1} \cdot \mathrm{min}^{-1}$ for women and $52.5 \pm$ $7.0 \mathrm{ml} \cdot \mathrm{kg}^{-1} \cdot \mathrm{min}^{-1}$ for men, indicating a good cardiorespiratory fitness level [2].

A short version (7 items) of the Italian version of the International Physical Activity Questionnaire [25] was administered to evaluate the level of PA for each subject. Women reported $6.0 \pm 3.9$ hours $\cdot$ week $^{-1}$ of vigorous and $4.2 \pm 3.5$ hours $\cdot$ week $^{-1}$ of moderate PA, while men reported $8.3 \pm 4.4$ hours $\cdot$ week $^{-1}$ of vigorous and $6.1 \pm 4.0$ hours $\cdot$ week $^{-1}$ of moderate PA.

Then, the subjects randomly performed 2 experimental sessions: ZC (a regular 60-min group class with an instructor) in the University gym (temperature: $26.9 \pm 2.1^{\circ} \mathrm{C}$; humidity: $46.0 \pm 10.1 \%$ ) and ZFR (a 60-min interactive lesson with Xbox Kinect 360, lesson one, long version) in the Sport and Exercise Physiology Laboratory (temperature: $27.2 \pm 2.9^{\circ} \mathrm{C}$; humidity: $45.0 \pm 10.1 \%$ ), organized with at least 3 days in between, during which the participants were required to refrain from moderate-to-vigorous PA. The power analysis performed on $\mathrm{VO}_{2}$ values from the pilot phase required a minimal sample size of 15 subjects.

\section{Participants}

Twenty healthy college students (age: 24-30 years; 12 women [age: $24.7 \pm 0.9$ years; body weight: 52.3 $\pm 3.3 \mathrm{~kg}$; body height: $159.5 \pm 4.3 \mathrm{~cm}$; BMI: $20.6 \pm$ $1.2 \mathrm{~kg} \cdot \mathrm{m}^{-2}$ ] and 8 men [age: $25.3 \pm 2.1$ years; body weight: $77.1 \pm 7.3 \mathrm{~kg}$; body height: $175.0 \pm 5.2 \mathrm{~cm}$; BMI: $25.3 \pm 3.3 \mathrm{~kg} \cdot \mathrm{m}^{-2}$ ]) volunteered to participate in the study. Each subject was informed about the testing procedures. Participants were included if reporting no previous experience in ZC or ZFR and excluded if they reported any current or pre-existing condition such as a cardiovascular, respiratory and/ or metabolic disease or physical injury. 


\section{Procedures}

During each experimental session, HR response was continuously recorded (Polar T31 transmitter, Polar Electro, Kempele, Finland) as average values of 5 seconds. The data were subsequently expressed as percentages of individual theoretical maximal $\mathrm{HR}$ (208 - 0.7 - age, \%HRmax) [26]. A telemetric open-circuit measurement system (K4b2 $\mathrm{b}^{2}$ Cosmed, Rome, Italy) was used to continuously record $\dot{\mathrm{VO}}_{2}$ data and estimate RER, MET, and EE $\left(\mathrm{kcal} \cdot \mathrm{kg}^{-1} \cdot \mathrm{min}^{-1}\right)$. EE was computed as a caloric equivalent for the average RER for time duration adopting the total net $\dot{\mathrm{VO}}_{2}$ as the mean $\dot{\mathrm{V}} \mathrm{O}_{2}$ for each session. Before each experimental session, known gas mixtures $\left(\mathrm{O}_{2}: 16.0 \%\right.$ and $20.9 \%$; $\mathrm{CO}_{2}: 5.0 \%$ and $0.03 \%$ ) were used to calibrate the gas analyser, while a 3-litre syringe (Hans Rudolph Inc., Dallas, USA) served to calibrate the flow meter. $\mathrm{K} 4 \mathrm{~b}^{2}$ showed intraclass reliability coefficients ranging from 0.7 to 0.9 [27]. $\mathrm{HR}$ and $\mathrm{VO}_{2}$ data of a representative subject are depicted in Figure 2.

Since recent evidence suggests that RPE scales are interchangeable [28, 29], in the present study the category-ratio 10 scale was used to monitor exercise inten-

a)

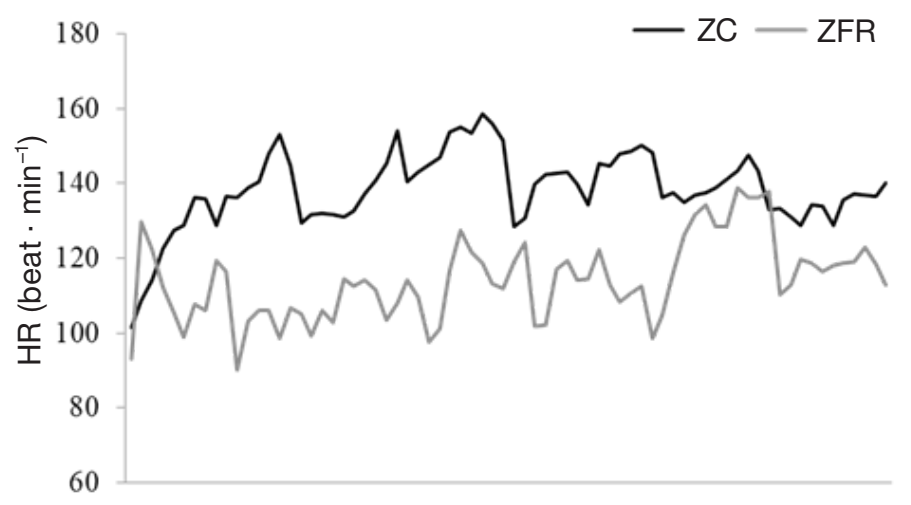

b)

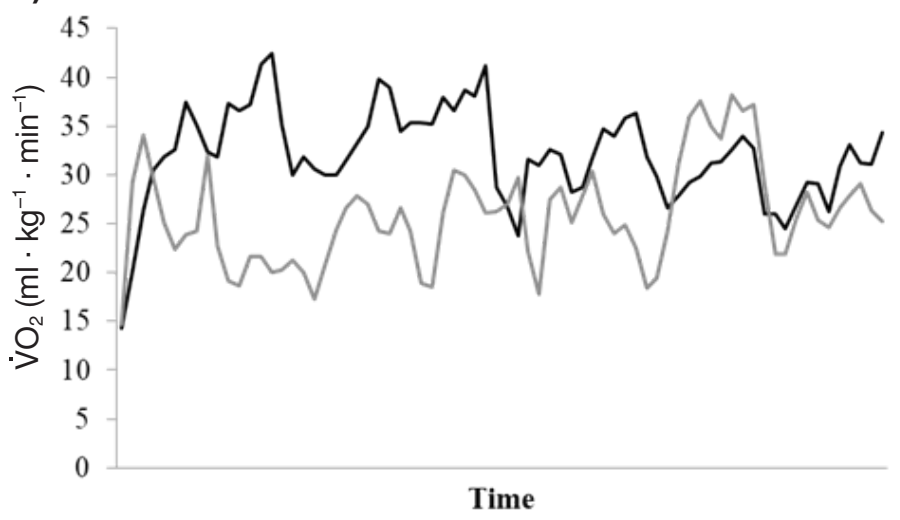

Figure 2. Heart rate (HR) (a) and oxygen consumption $\left(\dot{\mathrm{VO}}_{2}\right)$

(b) during Zumba ${ }^{\circledR}$ class (ZC) and Zumba ${ }^{\circledR}$ Fitness Rush

(ZFR) in a representative subject sity. Standardized instructions were provided prior to each session [30] and sRPE was collected approximately 30 minutes after the end of the session to ensure that the perceived exertion referred to the whole session rather than to the most recent exercise intensity, in line with similar research [17, 31]. sRPE training load was not calculated due to the fixed duration of each experimental session.

A 5-item Physical Activity Enjoyment Scale (PACES) was administered at the end of each ZC and ZFR session to evaluate the individuals' enjoyment while implementing the activities. The students rated the extent to which they agreed with each item on a 7-point Likert scale. Total responses were summed to give a score ranging from 5 to 35, and a percentage enjoyment score (\%PACES) was calculated, in line with similar research [11].

\section{Statistical analysis}

Normal distribution was verified by the ShapiroWilk test and means and standard deviations were calculated for all variables. Statistical significance was set at $p<0.05$. A two (sex: women vs. men) by two (modality: ZC vs. ZFR) analysis of variance (ANOVA) for repeated measures was applied to \%HRmax, $\dot{\mathrm{VO}}_{2}, \mathrm{RER}$, MET, EE, sRPE, PACES, and \%PACES values. If the overall $\mathrm{F}$ test was significant, the post-hoc Fisher protected least significant difference comparisons were used. Cohen's $(d)$ effect sizes $(E S)$ were also calculated. An $E S$ less than 0.2 was considered trivial, from 0.2 to 0.5 small, greater than 0.5 to 0.8 moderate, and greater than 0.8 large [32]. The Stata statistical software version 14.1 (StataCorp, College Station, USA) was used for statistical analysis.

\section{Ethical approval}

The research related to human use has complied with all the relevant national regulations and institutional policies, has followed the tenets of the Declaration of Helsinki, and has been approved by the Institutional Review Board of Department of Human Sciences, Society and Health of the University of Cassino and Lazio Meridionale (approval No.: 26898.2019.11.27; date: December 4, 2019).

\section{Informed consent}

Informed consent has been obtained from all individuals included in this study. 


\section{Results}

The \%HRmax, $\dot{\mathrm{VO}}_{2}$, RER, MET, EE, sRPE, PACES, and \%PACES data of ZC and ZFR in women and men are presented in Table 1.

Main effects for sex $(p=0.02)$ and modality $(p<$ 0.0001 ) emerged for \%HRmax (Figure 3), with women showing higher values than men and ZC showing higher values than ZFR. EE presented main effects for sex $(p<0.0001)$ and modality $(p=0.0002)$, with higher values in men and in ZC. Main effect $(p=0.0001)$ for modality emerged also for $\dot{\mathrm{VO}}_{2}$ and METs (Figure 4), with higher values in $\mathrm{ZC}$ regardless of sex.

Finally, no significant differences were observed for RER, sRPE, PACES, or \%PACES in relation to modality and sex.

\section{Discussion}

Aiming to explore alternative and engaging forms of home-based PA during the on-going coronavirus disease quarantine, this study compared physiological and psychological responses in ZC with those in ZFR. The main findings showed that: (a) ZC elicited higher cardiovascular and metabolic responses than ZFR; (b) men presented lower HR responses and higher EE values than women regardless of modality game; and (c) no differences emerged for RER, sRPE, PACES, and \%PACES. Regardless of sex, in the present study, significantly higher physiological responses were found in ZC. Although ZC elicited higher cardiovascular and metabolic responses regardless of sex, ZFR, classified as a moderate-to-vigorous activity, could be used to maintain regular PA and routinely exercising in a safe home environment, maintaining safe distances among individuals during the coronavirus outbreak.

Differences in ZC and ZFR could be expected due to the enthusiasm of the instructor providing real-time feedbacks and encouragements and other participants practising simultaneously during $\mathrm{ZC}$, resulting in a further stimulus towards subjects, helping and encouraging them to improve exercise intensity. However,

Table 1. Means, standard deviations, percentages of differences, $p$ values, and effect sizes $(d)$ of physiological and psychological parameters of Zumba ${ }^{\circledR}$ class and Zumba ${ }^{\circledR}$ Fitness Rush in women and men

WOMEN

\begin{tabular}{lccrcc}
\hline Variable & ZC & ZFR & \% diff & $p$ & Cohen's $d$ \\
\hline \%HRmax & $80.3 \pm 6.3$ & $72.1 \pm 5.6^{*}$ & -10.2 & 0.004 & 1.382 (large) \\
$\dot{\mathrm{VO}}\left(\mathrm{ml} \cdot \mathrm{kg}^{-1} \cdot \mathrm{min}^{-1}\right)$ & $25.5 \pm 1.6$ & $23.0 \pm 2.8^{*}$ & -9.8 & 0.004 & 1.096 (large) \\
$\mathrm{RER}$ & $0.95 \pm 0.03$ & $0.91 \pm 0.06$ & -4.2 & 0.17 & 0.843 (large) \\
$\mathrm{MET}$ & $7.3 \pm 0.5$ & $6.6 \pm 0.8^{*}$ & -9.6 & 0.004 & 1.049 (large) \\
$\mathrm{EE}\left(\mathrm{kcal} \cdot \mathrm{min}^{-1}\right)$ & $6.6 \pm 0.6$ & $5.9 \pm 0.9^{*}$ & -10.6 & 0.005 & 0.915 (large) \\
$\mathrm{sRPE}$ & $4.7 \pm 1.4$ & $4.1 \pm 2.2$ & -12.8 & 0.32 & 0.325 (small) \\
PACES & $30.7 \pm 4.2$ & $28.2 \pm 5.6$ & -8.1 & 0.26 & 0.505 (moderate) \\
$\%$ PACES & $87.8 \pm 12.1$ & $80.5 \pm 15.9$ & -8.3 & 0.26 & 0.517 (moderate) \\
\hline
\end{tabular}

$M E N$

\begin{tabular}{lccrcc}
\hline Variable & ZC & ZFR & \% diff & $p$ & Cohen's $d$ \\
\hline \%HRmax & $73.5 \pm 5.0$ & $65.0 \pm 8.2^{* \#}$ & -11.6 & 0.01 & 1.245 (large) \\
$\dot{\mathrm{VO}}\left(\mathrm{ml} \cdot \mathrm{kg}^{-1} \cdot \mathrm{min}^{-1}\right)$ & $25.6 \pm 4.7$ & $21.7 \pm 4.0^{*}$ & -15.2 & 0.02 & $0.894($ large) \\
$\mathrm{RER}$ & $0.95 \pm 0.05$ & $0.93 \pm 0.06$ & -2.1 & 0.42 & $0.362(\mathrm{small})$ \\
$\mathrm{MET}$ & $7.3 \pm 1.3$ & $6.2 \pm 1.1^{*}$ & -15.1 & 0.02 & $0.914($ large) \\
$\mathrm{EE}\left(\mathrm{kcal} \cdot \mathrm{min}^{-1}\right)$ & $9.7 \pm 1.5^{\#}$ & $8.2 \pm 1.3^{* \#}$ & -15.5 & 0.02 & 1.069 (large) \\
$\mathrm{sRPE}$ & $3.8 \pm 1.3$ & $4.5 \pm 1.0$ & 18.4 & 0.18 & 0.604 (moderate) \\
PACES & $31.7 \pm 4.0$ & $31.3 \pm 4.7$ & -1.3 & 0.75 & 0.092 (trivial) \\
\%PACES & $90.5 \pm 11.4$ & $89.3 \pm 13.6$ & -1.3 & 0.75 & 0.096 (trivial) \\
\hline
\end{tabular}

ZC - Zumba ${ }^{\oplus}$ class, ZFR - Zumba ${ }^{\oplus i t n e s s ~ R u s h, ~ \% ~ d i f f ~-~ p e r c e n t a g e s ~ o f ~ d i f f e r e n c e s, ~ \% H R m a x ~-~ p e r c e n t a g e s ~ o f ~ h e a r t ~ r a t e ~}$ maximum, $\mathrm{VO}_{2}$ - oxygen consumption, RER - respiratory exchange ratio, MET - metabolic equivalent task,

EE - energy expenditure, sRPE - session rating of perceived exertion, PACES - Physical Activity Enjoyment Scale score, \%PACES - Physical Activity Enjoyment Scale percentage score

* differences from ZC

* differences from women 


\section{HUMAN MOVEMENT}

C. Cortis et al., Home-based physical activity

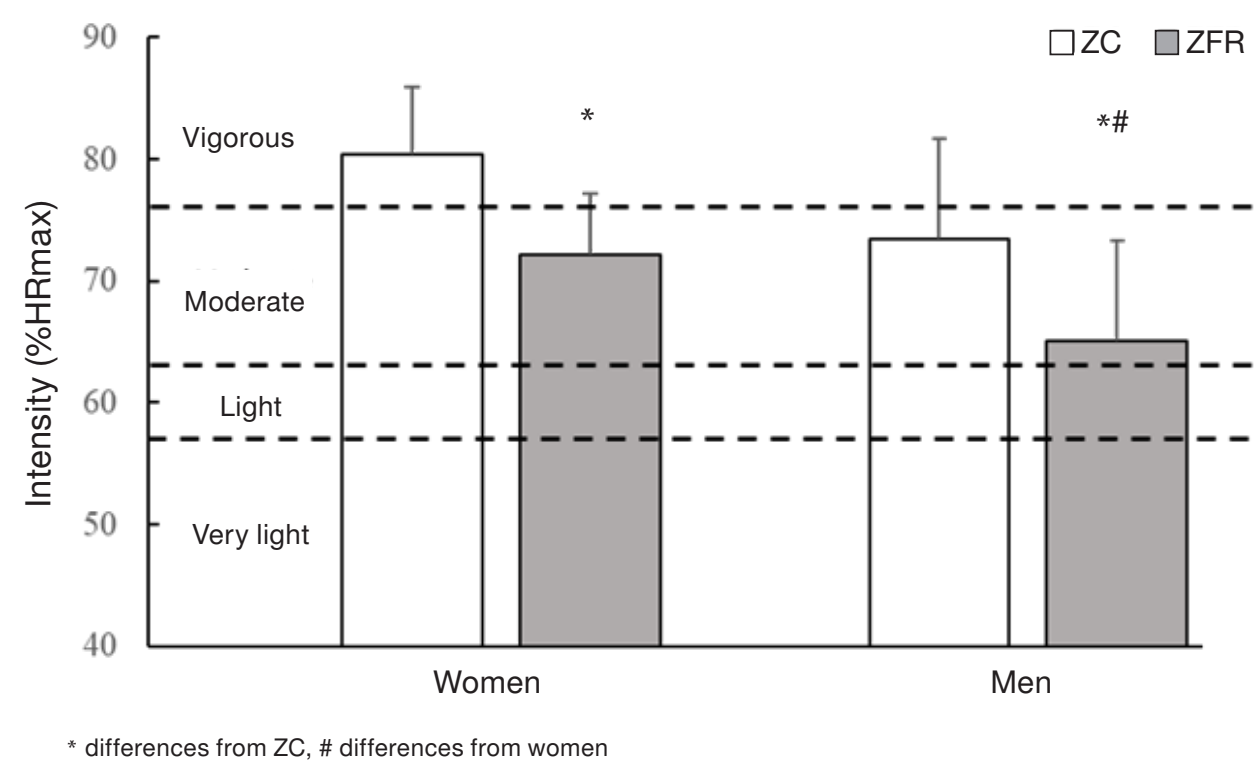

Figure 3. Mean and standard deviation of the exercise intensity expressed as percentage of maximum heart rate (\%HRmax) during Zumba ${ }^{\circledR}$ class (ZC) and Zumba ${ }^{\circledR}$ Fitness Rush (ZFR) in women and men. Dash lines represent the intensity classification according to American College of Sports Medicine [2]

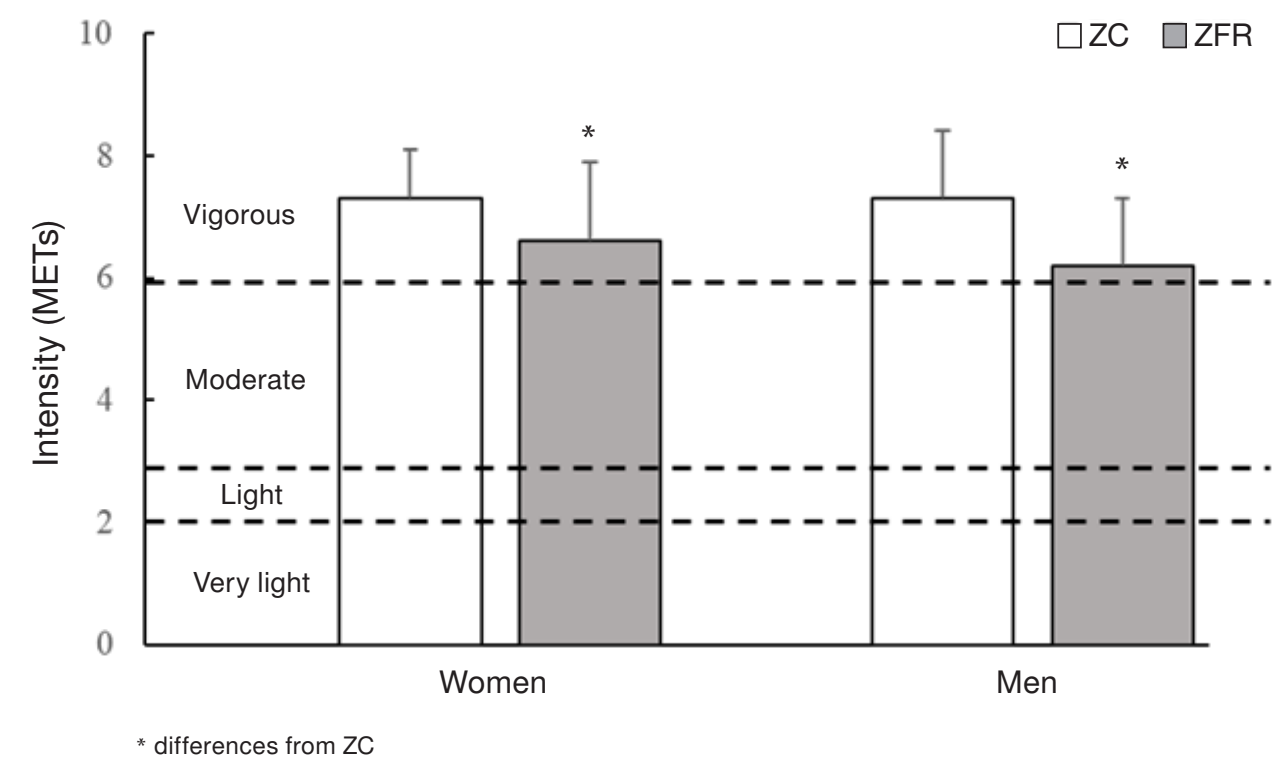

Figure 4. Mean and standard deviation of the exercise intensity expressed in metabolic equivalent tasks (METs) during Zumba ${ }^{\circledR}$ class (ZC) and Zumba ${ }^{\circledR}$ Fitness Rush (ZFR) in women and men. Dash lines represent the intensity classification according to American College of Sports Medicine [2]

in ZFR, players follow the instructors' clues and the choreography, collecting stars when playing well to increase their score, and before every movement change, players receive a visual cue, thus being able to follow the instructor in due time, without feeling lost [17]. Moreover, a previous study reported no difference between single- and multi-player modality [17], which suggests that the rhythm of the music in ZFR plays a crucial role in imposing a time constraint, ensuring the player to follow the virtual instructor and the choreography and thus limiting the variability owing to the presence of a real instructor and other people exercising [19].

In accordance with \%HRmax, ZFR could be classified [2] as a moderate-intensity activity in men and women, whereas $\mathrm{ZC}$ as vigorous and moderate in women and men, respectively. In line with a previous study [21], significantly higher $\mathrm{HR}$ and $\dot{\mathrm{VO}}_{2}$ values were found in ZC than in ZFR. Both activities showed MET values comparable with the acute cardiovascular responses during a session of ZC $[33,34]$ and Zumba ${ }^{\circledR}$ played with several forms of AVGs [21, 33], respectively. 
In particular, with regard to MET values, findings suggest that independently of sex, ZC and ZFR could be classified [2] as vigorous activity. Finally, RER data, as a surrogate of substrate utilization, indicate a carbohydrate oxidation ranging from 70 to $84 \%$ and fat oxidation ranging from 29 to $16 \%$ [35]. Regardless of the modality, men rated the lessons as 'somewhat hard' according to the category-ratio 10 scale, corresponding to 13 on the 6-20 RPE scale [29], whereas women rated ZC as 'hard' and ZFR as 'somewhat hard' according to the category-ratio 10 scale, corresponding, respectively, to 14 and 13 on the 6-20 scale [29]. Only a few studies used sRPE to evaluate training load during ZC and ZFR [17], reporting results comparable with the present study (average values of 4).

To maintain a healthy lifestyle, an EE of at least $300 \mathrm{kcal}$ per session is suggested [2]. According to the findings of the present study, men will need 31 minutes of ZC or 36 minutes of ZFR, whereas women will need 45 minutes of ZC or 51 minutes of ZFR in each training session. Although ZFR sessions will need to be longer than those of ZC, the difference is minimal, thus making AVG suitable to reach adequate PA levels, especially when preventive measures are needed to ensure isolation and limit interpersonal contacts.

Some limitations should be acknowledged for this study. The sample size was relatively small, but in line with recent similar research studies. Only an adult sample was analysed; thus, future studies should investigate also youth and older subjects. The activity was limited to Zumba ${ }^{\circledast}$, so future research should include other forms of PA focusing on selected aspects of the fitness components, such as aerobic, strength, endurance, power. In the present study, a cross-sectional approach was favoured, and future longitudinal studies should be carried out to provide information also regarding long-term effects of such forms of PA. AVGs are a non-supervised PA, while during quarantine, also other forms of distance PA, such as the ones supervised by an instructor online, have become popular. Therefore, future studies should look at the impact of non-supervised vs. online-supervised forms of PA.

\section{Conclusions}

From a practical point of view, companies and stakeholders should foresee the possibility to modify choreographies and routines by adjusting the physiological demands of the proposed activity to ensure the EE required [2]. For example, if the interaction between AVGs console and HR monitor were possible, based on the real-time HR data of the player, the AVG could increase or decrease velocity of execution, choreography, and movement to ensure a proper EE during the session. Alternatively, as sRPE is recommended to prescribe, monitor, and regulate exercise intensity [2], being easier to collect than HR, sRPE values could be monitored (by showing the RPE scale on the screen, with the player indicating their perceived exertion), thus adapting the intensity of a session in accordance with the player's actual perception and fitness status. Moreover, as during the quarantine and isolation period, interpersonal contacts should be limited [6], physicians could use the collected data to monitor the fitness status and progress of people without needing to get in contact. More generally, playing AVGs could be used to counteract sedentary behaviours as it may be an attractive fitness activity for those who do not feel comfortable exercising in a public or group settings, not only when isolation is necessary.

\section{Funding}

This research received no external funding.

\section{Acknowledgments}

The authors would like to express their gratitude to the subjects involved in the study for their committed participation.

\section{Disclosure statement}

No author has any financial interest or received any financial benefit from this research.

\section{Conflict of interest}

The authors state no conflict of interest.

\section{References}

1. World Health Organization. Physical activity. 2018. Available from: https://www.who.int/news-room/ fact-sheets/detail/physical-activity.

2. American College of Sports Medicine. ACSM's guidelines for exercise testing and prescription, $10^{\text {th }} \mathrm{ed}$. Philadelphia: Wolters Kluwer; 2017.

3. Bushman BA. Physical activity guidelines for Americans. The relationship between physical activity and health. ACSMs Health Fit J. 2019;23(3):5-9; doi: 10.1249/FIT.0000000000000472.

4. Wang C, Horby PW, Hayden FG, Gao GF. A novel coronavirus outbreak of global health concern. Lancet. 2020;395(10223):470-473; doi: 10.1016/S0140-6736 (20)30185-9.

5. Sohrabi C, Alsafi Z, O’Neill N, Khan M, Kerwan A, Al-Jabir A, et al. World Health Organization declares global emergency: a review of the 2019 novel coronavirus (COVID-19). Int J Surg. 2020;76:71-76; doi: 10.1016/j.ijsu.2020.02.034. 
6. World Health Organization. Coronavirus disease (COVID-19) advice for the public. 2020. Available from: https://www.who.int/emergencies/diseases/novelcoronavirus-2019/advice-for-public.

7. Chen P, Mao L, Nassis GP, Harmer P, Ainsworth BE, Li F. Coronavirus disease (COVID-19): the need to maintain regular physical activity while taking precautions. J Sport Health Sci. 2020;9(2):103-104; doi: 10.1016/j.jshs.2020.02.001.

8. Rizzo AS, Lange B, Suma EA, Bolas M. Virtual reality and interactive digital game technology: new tools to address obesity and diabetes. J Diabetes Sci Technol. 2011;5(2):256-264; 10.1177/193229681100500209.

9. Warburton DER. The health benefits of active gaming: separating the myths from the virtual reality. Curr Cardiovasc Risk Rep. 2013;7:251-255; doi: 10.1007/ s12170-013-0322-0.

10. Gao Z. Fight fire with fire? Promoting physical activity and health through active video games. J Sport Health Sci. 2017;6(1):1-3; doi: 10.1016/j.jshs.2016.11.009.

11. Graves LEF, Ridgers ND, Williams K, Stratton G, Atkinson G, Cable NT. The physiological cost and enjoyment of Wii Fit in adolescents, young adults, and older adults. J Phys Act Health. 2010;7(3):393-401; doi: 10.1123/jpah.7.3.393.

12. McDonough DJ, Pope ZC, Zeng N, Lee JE, Gao Z. Comparison of college students' energy expenditure, physical activity, and enjoyment during exergaming and traditional exercise. J Clin Med. 2018;7(11):433; doi: $10.3390 / \mathrm{jcm} 7110433$.

13. Whitehead A, Johnston H, Nixon N, Welch J. Exergame effectiveness: what the numbers can tell us. Proc. $5^{\text {th }}$ ACM SIGGRAPH Symposium on Video Games - Sandbox '10. New York: ACM Press; 2010; 55-62; doi: 10.1145/1836135.1836144.

14. Cortis C, Puggina A, Pesce C, Aleksovska K, Buck C, Burns C, et al. Psychological determinants of physical activity across the life course: a "DEterminants of DIet and Physical ACtivity” (DEDIPAC) umbrella systematic literature review. PLoS One. 2017;12(8):e0182709; doi: 10.1371/journal.pone.0182709.

15. Bailey BW, McInnins K. Energy cost of exergaming: a comparison of the energy cost of 6 forms of exergaming. Arch Pediatr Adolesc Med. 2011;165(7):597-602; doi: 10.1001/archpediatrics.2011.15.

16. Tate DF, Lyons EJ, Valle CG. High-tech tools for exercise motivation: use and role of technologies such as the Internet, mobile applications, social media, and video games. Diabetes Spectr. 2015;28(1):45-54; doi: 10.2337/ diaspect.28.1.45.

17. Giancotti GF, Fusco A, Rodio A, Capranica L, Cortis C. Energy expenditure and perceived exertion during active video games in relation to player mode and gender. Kinesiology. 2018;50(1):18-24; doi: 10.26582/k.50.1.3.

18. Tietjen AMJ, Devereux GR. Physical demands of exergaming in healthy young adults. J Strength Cond Res.
2019;33(7):1978-1986; doi: 10.1519/JSC.000000000 0002235 .

19. Schneekloth B, Brown GA. Comparison of physical activity during Zumba with a human or video game instructor. Int J Exerc Sci. 2018;11(4):1019-1030.

20. Da Silva Neves LE, Da Silva Cerávolo MP, Silva E, De Freitas WZ, Da Silva FF, Higino WP, et al. Cardiovascular effects of Zumba ${ }^{\circledR}$ performed in a virtual environment using XBOX Kinect. J Phys Ther Sci. 2015; 27(9):2863-2865; doi: 10.1589/jpts.27.2863.

21. Howe CA, Barr MW, Winner BC, Kimble JR, White JB. The physical activity energy cost of the latest active video games in young adults. J Phys Act Health. 2015; 12(2):171-177; doi: 10.1123/jpah.2013-0023.

22. Foster C, Cortis C, Fusco A, Bok D, Boullosa DA, Capranica L, et al. The future of health/fitness/sports performance. Front J Soc Technol Environ Sci. 2017;6(3): 187-211; doi: 10.21664/2238-8869.2017v6i3.p187-211.

23. Soltani P, Figueiredo P, Vilas-Boas JP. Does exergaming drive future physical activity and sport intentions? J Health Psychol. 2020: 1359105320909866; doi: $10.1177 / 1359105320909866$.

24. Sadhan B, Koley S, Sandhu JS. Relationship between cardiorespiratory fitness, body composition and blood pressure in Punjabi collegiate population. J Hum Ecol. 2007;22(3):215-219; doi: 10.1080/09709274.2007. 11906024.

25. Mannocci A, Di Thiene D, Del Cimmuto A, Masala D, Boccia A, De Vito E, et al. International Physical Activity Questionnaire: validation and assessment in an Italian sample. Ital J Public Health. 2010;7(4):369-376; doi: 10.2427/5694.

26. Tanaka H, Monahan KD, Seals DR. Age-predicted maximal heart rate revisited. J Am Coll Cardiol. 2001; 37(1):153-156; doi: 10.1016/S0735-1097(00)01054-8.

27. Duffield R, Dawson B, Pinnington HC, Wong P. Accuracy and reliability of a Cosmed K4b2 portable gas analysis system. J Sci Med Sport. 2004;7(1):11-22; doi: 10.1016/S1440-2440(04)80039-2.

28. Arney BE, Glover R, Fusco A, Cortis C, de Koning JJ, van Erp T, et al. Comparison of RPE (rating of perceived exertion) scales for session RPE. Int J Sports Physiol Perform. 2019;14(7):994-996; doi: 10.1123/ijspp.20180637.

29. Arney BE, Glover R, Fusco A, Cortis C, de Koning JJ, van $\operatorname{Erp} \mathrm{T}$, et al. Comparison of rating of perceived exertion scales during incremental and interval exercise. Kinesiology.2019;51(2):150-157; doi:10.26582/k.51.2.1.

30. Borg G. Borg's perceived exertion and pain scales. Champaign: Human Kinetics; 1998.

31. Foster C, Heimann KM, Esten PL, Brice G, Porcari JP. Differences in perceptions of training by coaches and athletes. S Afr J Sports Med. 2001;8(2):3-7.

32. Cohen J. Statistical power analysis. Curr Dir Psychol Sci. 1992;1(3):98-101; doi: 10.1111/1467-8721.ep107 68783. 
33. Delextrat A, Neupert E. Physiological load associated with a Zumba ${ }^{\circledR}$ fitness workout: a comparison pilot study between classes and a DVD. J Sports Sci. 2016;34(1): 47-55; doi: 10.1080/02640414.2015.1031162.

34. Luettgen M, Foster C, Doberstein S, Mikat R, Porcari J. Zumba $^{\circledR}$ : is the "fitness-party" a good workout? J Sports Sci Med. 2012;11(2):357-358.

35. Porcari J, Bryant C, Comana F. Exercise physiology. Philadelphia: F.A. Davis Company; 2015. 